\title{
GEODÉSICAS NA ARQUITETURA: da representação gráfica à construção em escala natural ${ }^{1}$
}

\author{
GEODESICS IN ARCHITECTURE: from \\ graphic representation to natural \\ scale construction
}

${ }^{1}$ Versão expandida do artigo selecionado nos Anais do Graphica 2019

\author{
Frederico Braida \\ Doutor em Design \\ Docente, Universidade Federal de \\ Juiz de Fora, Juiz de Fora, Brasil; \\ Universidade Tecnológica Federal do \\ Paraná, Toledo, Brasil \\ frederico.braida@arquitetura.ufjf.br
}

\section{RESUMO:}

Este artigo aborda o tema das geodésicas adotadas como objetos arquitetônicos. 0 principal objetivo é evidenciar as potencialidades que as geodésicas possuem para despertar o interesse de alunos de Arquitetura e Urbanismo para a indissociável relação entre forma geométrica, sistema estrutural e composição plástica. Metodologicamente, este artigo é fruto de uma revisão de literatura, bem como da apresentação de algumas atividades pedagógicas que abrangem desde a representação gráfica até a construção em escala natural de domos geodésicos, para as quais são demandados os conhecimentos sobre a geometria gráfica.

Palavras-chave: geodésica; geometria; representação gráfica; construção.

\section{ABSTRACT:}

This paper approaches the theme of geodesics adopted as architectural objects. The main aim is to present the potential of the geodesics to arouse the interest of Architecture and Urbanism students to the inextricable relation between geometric form, structural system and plastic composition. Methodologically, this paper is the result of a literature review, as well as the presentation of some pedagogical activities that range from the graphic representation to the natural scale construction of geodesic domes, for which knowledge about graphic geometry is required.

Keywords: geodesic; geometry; representation; construction. 


\section{INTRODUÇÃO}

As geodésicas são formas geométricas poliédricas já conhecidas há séculos. No entanto, sua utilização no campo da Arquitetura e do Urbanismo datam do início do século $\mathrm{XX}$, sendo massivamente exploradas pelo arquiteto, matemático e designer, entre outras qualificações, Richard Buckminster Fuller (1895-1983). Desde então, as cúpulas geodésicas (ou domos geodésicos) têm sido empregadas recorrentemente em edifícios e estruturas arquitetônicas.

As estruturas geodésicas também têm estado presente na formação dos arquitetos e urbanistas, como tópico abordado nos cursos de graduação, seja nas disciplinas de sistemas estruturais/construtivos e/ou de história e teoria, seja nas disciplinas de projeto e/ou de representação gráfica. Nota-se, portanto, que as geodésicas podem constituir-se como temática interdisciplinar, uma vez que suscitam a discussão integradora entre diferentes saberes. É sob esse viés que as geodésicas são tratas neste artigo: como objetos capazes de articular conhecimentos geométricos, tectônicos e plásticos, os quais, de forma subjacente, demandam os saberes da geometria gráfica.

Deve-se destacar que, no campo da Arquitetura, faz-se indispensável que os alunos compreendam as relações existentes entre forma geométrica, sistema estrutural e composição plástica. Porém, não é incomum que esses temas sejam tratados separadamente, refletindo sua distribuição fragmentada em disciplinas curriculares desarticuladas, por vezes oferecidas por departamentos especializados, cujos diálogos costumam ser rarefeitos.

Embora deva-se reconhecer a existência de diversas iniciativas e propostas pedagógicas que buscam superar essa fragmentação, a falta de uma formação holística ainda persiste em várias instituições de ensino superior, reforçando a produção de abismos entres os grupos de conteúdos reunidos em diferentes subáreas, tais como: (a) projeto, (b) representação e expressão gráfica, (c) história e teoria e (d) técnicas e tecnologias. É nesse sentido que Laverde e Salado (2012, p. 2) afirmam haver uma "dificuldade de transferência dos conhecimentos adquiridos na área tecnológica para o desenvolvimento de projetos arquitetônicos em Atelier, [...] ficando nítido o distanciamento entre a atividade projetual e a prática construtiva".

Levando em consideração essas questões, Laverde e Salado (2012, p. 2), a partir de uma experiência desenvolvida na Universidade Federal de Uberlândia, apresentam a construção de uma cúpula geodésica como um exercício de "aproximação entre a teoria e as atividades práticas no ensino de arquitetura e urbanismo". As autoras propõem, portanto, a produção de um domo geodésico como um exemplo de alternativa para a superação da disciplinarização dos conteúdos.

Assim, as geodésicas apresentam-se como tópico oportuno para a compreensão da necessária integração dos saberes. Em suas conclusões sobre os estudos das geodésicas, Diniz (2006, p. 134) afirma que

na verdade este é um território de estudos onde a arquitetura e a engenharia não podem se afastar uma da outra, chegando a ser complementares e quase coincidentes as buscas e os resultados efetuados por cada uma destas disciplinas. 
As cúpulas geodésicas trazem em si a complementação entre Geometria, Engenharia e Arquitetura, contribuindo para a superação da crença "de que engenheiros não se interessam por arquitetura e que os arquitetos desprezam a engenharia" (VASCONCELOS, 2006, p. 9). Também está engendrada nas geodésicas a indissociabilidade entre forma e estrutura. Vale ressaltar que, segundo Amorim (2014, p. 139),

a estrutura de uma edificação é parte integrante da síntese das decisões formais que origina a materialização do espaço. Aceitar essa afirmação significa dizer que não há diferença entre concepção formal e estrutural.

Portanto, diante desse cenário, o principal objetivo deste artigo é apresentar algumas possibilidades de aplicação de exercícios que explorem as geodésicas, desde os aspectos da representação gráfica até a construção em escala natural, a partir de uma sequência didática desenvolvida no âmbito da disciplina "Estudo da Forma", ministrada no primeiro período do curso de Arquitetura e Urbanismo da Universidade Federal de Juiz de Fora (UFJF), com vistas a reforçar as potencialidades das geodésicas para a integração dos saberes.

\section{GEODÉSICAS E A GEOMETRIA}

A palavra "geodésica" é formada pelo prefixo "geo-", que significa "terra". "Para a Matemática, o termo "geodésica" (do grego geo=terra e daiein=dividir) se refere a medições e cálculos realizados sobre superfícies curvas, como a superfície do nosso planeta" (MARQUES, 2016).

As geodésicas "são poliedros, cujos vértices estão sobre a superfície de uma esfera” (MONTENEGRO, 1991, p. 76). Elas são compostas por barras e nós. É interessante notar que os nós também são estruturas poliédricas, como bem evidenciado por Montenegro (1984, p. 85). "Quanto maior o número de vértices (e de faces) mais o poliedro se aproxima da superfície da esfera" (MONTENEGRO, 1984, p. 88). Partindo-se de um cubo e, ao serem realizadas sucessivas transformações subtrativas (cortes) nos vértices, passa-se pela construção de alguns poliedros, podendo-se chegar bem próximo de uma geometria esférica.

De forma mais específica, pode-se dizer que um domo geodésico é

um poliedro (ou sólido) irregular gerado a partir da projeção das faces de poliedros regulares, composta por elementos triangulares justapostos e organizados de forma que todos os seus vértices sejam congruentes com um grande círculo da esfera" (MARQUES, 2016).

Também, segundo Diniz (2006, p.32), uma estrutura geodésica é uma "trama composta por polígonos planos diversos onde a interseção das linhas retas destes polígonos, ou seus vértices, coincidem com uma superfície esférica ou oval". Os domos geodésicos possuem, ainda, como característica formal a unidade, pois são compostos pela repetição de partes semelhantes: por triângulos (VANDYKE, 1985, p. 26).

A complexidade das geodésicas pode variar em função as escolhas dos poliedros que compõem a superfície.

Uma Superfície ou Estrutura Geodésica pode estar composta apenas por polígonos regulares planos como triângulos ou quadrados, onde as linhas têm a 
mesma dimensão, ou também por polígonos irregulares de diferentes conformações, e mesmo não planos ou espaciais, gerando superfícies e tramas estruturais muito mais complexas com duas ou mais camadas (DINIZ, 2006, p.32 e 33).

A frequência $(\mathrm{V})$ das geodésicas interfere na complexidade das mesmas. A frequência diz respeito ao número de triângulos em que a superfície se subdivide. A frequência de uma esfera geodésica corresponde ao número de divisões do arco da esfera de origem. Ela influencia no tamanho dos triângulos e das varas (ou barras) que compõem os triângulos. Alguns exemplos de variação das faces podem ser encontrados no site “Geodesics UNLTD” (ver http://www.geodesics-unlimited.com/face-variations.htm).

Para a construção de domos geodésicos, recorrentemente utilizam-se frequências pares, pois elas são capazes de gerar bases regulares quando as geodésicas são seccionadas nos hemisférios. Atenta-se, também, para o fato de que o sólido mais utilizado na construção de geodésicas é o icosaedro, em função da ótima relação entre o volume de material a ser gasto e a área da superfície da estrutura (MARQUES, 2016).

Como se vê, e conforme amplamente demonstrado por Fuller (2002), ao se explorar as geodésicas, vários conteúdos do universo da Geometria são ativados. Nesse mesmo sentido, Lotufo e Lopes (1981) apresentam, no livro intitulado "Geodésica e cia", de forma detalhada, diversos aspectos geométricos (e matemáticos) envolvidos na construção de geodésicas. De acordo com os autores, conhecendo a Geometria, podemos "entender que a geodésica é mais que uma esfera, que ela pode assumir as mais variadas formas e que realmente ela apresenta vantagens estruturais" (LOTUFO; LOPES, 1981, [p. 2]).

\section{GEODÉSICAS: ENGENHARIA E ARQUITETURA}

Embora a bibliografia sobre cúpulas geodésicas não seja expressiva em termos quantitativos, Diniz (2006, p.24-31) apresentou uma revisão de literatura que contempla essa temática dentro dos campos da Engenharia e Arquitetura. Também Verschleisser (2008) levantou o estado da arte do conceito "tensegrity" ("tensegridade") estudado por Fuller, suas relações com as estruturas geodésicas e suas aplicações no campo do Design.

De acordo com Engel (2001, p. 19), "a estrutura é o primeiro e único instrumento para gerar forma e espaço na arquitetura. Por esta função, a estrutura torna-se um meio essencial para modelar o meio material do homem". Eis aí uma das principais contribuições da estrutura para o campo da Arquitetura.

Para Lopes, Bogéa e Rebello (2006, p. 44, grifos nossos),

as possibilidades espaciais e estruturais dependem da geometria do elemento estrutural como base de projeto. Blocos, barras e lâminas são tipologias básicas dessas geometrias estruturais, uma relação dada pela proporção de sua forma. Cada uma delas trará especificidades no comportamento da estrutura. Identificar a geometria dos elementos que compõem uma estrutura nos permite uma eficiente estratégia de análise a partir desses elementos: uma espécie de chave de leitura.

Segundo Lopes, Bogéa e Rebello (2006, p. 57), as barras são as mais ecléticas e versáteis geometrias, pois elas estão "presentes desde as peças de madeira que elevam as tendas dos nômades, ou estruturavam as ocas indígenas, até as recentes treliças em aço" 
e, quando associadas, permitem múltiplas possibilidades estruturais. Ilustrando essa versatilidade das barras, sua variedade formal, Amorim (2014, p. 143) nos lembra que as barras estão presentes nas vigas, pilares, colunas, montantes, dutos, treliças, geodésicas e em outras composições feitas preliminarmente de linhas.

As cúpulas sempre despertaram o interesse dos arquitetos, sobretudo quando buscam soluções para grandes coberturas. De acordo com Montenegro (1984, p. 80), a partir do domínio da técnica construtiva com arcos, foi possível o desenvolvimento das cúpulas, originadas a partir da rotação desses elementos. As cúpulas são estruturas abobadadas, geralmente de planta circular e diretrizes parabólicas, circulares ou outras curvas contínuas (VILLASUSO, 2009, p. 45) e que, normalmente, apresentam a forma de uma porção esférica, "construída de modo a exercer esforços iguais em todas as direções" (CHING, 2000, p. 70).

$\mathrm{Na}$ história da arquitetura, destacam-se algumas cúpulas como, por exemplo, a cúpula do Panteão de Adriano, em Roma, e o transepto da igreja de Santa Maria del Fiore, em Florença, de Brunelleschi. No entanto, Montenegro (1984, p. 88) nos lembra que essas primeiras cúpulas eram praticamente fechadas, ou abertas somente no topo (configurando lanternim) e espessas. Mas, com o desenvolvimento tecnológico, sobretudo computacional, tornou-se possível "o cálculo rápido das malhas espaciais (treliças; estruturas ou reticulados espaciais são outros nomes usados) e permitiu, igualmente, o cálculo da cúpula geodésica (ou, simplesmente, geodésica)" (MONTENEGRO, 1984, p. 88). Com isso, tal como uma malha espacial, as cúpulas puderam ser construídas com barras e nós.

Ainda de acordo com Montenegro (1984, p. 90), bem como segundo Lotufo e Lopes (1981, [p. 4]), embora a figura geométrica geodésica já fosse conhecida há muitos séculos, a primeira cúpula geodésica usada como cobertura data de 1922, empregada no Planetário de Jena, na Alemanha Oriental, calculada por Walter Bauersfeld. No entanto, os estudos sistemáticos que levaram ao cálculo e à fabricação industrial das geodésicas são do arquiteto Richard Buckminster Fuller.

Mesmo que Fuller não seja o inventor propriamente dito da geodésica, o que ele fez foi dar um sentido a essa estrutura, "descobrindo suas leis formadoras, construindo e divulgando suas propriedades" (LOTUFO; LOPES, 1981, [p. 4]). "A partir de 1945, Fuller voltou sua atenção para o estudo da trigonometria esférica. Ele intrigava-se com as formas geodésicas encontradas na natureza, desde as milhares de bolhas num pouco de espuma até os próprios planetas" (LOTUFO; LOPES, 1981, [p. 3]).

Todo o pensamento de Fuller está registrado, entre outros lugares, no livro de sua autoria intitulado "Synergetics: explorações em torno da geometria do pensar", publicado primeiramente em 1975, pela Editora Macmillan. Esse livro (ver FULLER, 2002) traz as "suas ideias sobre uma geometria inspirada nos padrões energéticos e formais da natureza definindo um sistema matemático experimentado não só por abstrações e cálculos, mas por experimentações físicas e reais" (DINIZ, 2006, p. 25).

Fuller baseou-se na teoria dos sistemas. "Essa abordagem se contrapõe à visão mecanicista e fragmentada do universo, na tradição cartesiana de se analisar cada elemento separadamente, a fim de se compreender o todo" (SILVA; FARBIARZ, p. 2000). Dentre as proposições mais importantes está o fato de que, "partindo do cálculo 
matemático, Fuller chegou à esquematização do processo de divisão da esfera em triângulos" (LOTUFO; LOPES, 1981, [p. 3]) (Figura 1).

Figura 1: Estudos do arquiteto Richard Buckminster Fuller sobre as geodésicas.

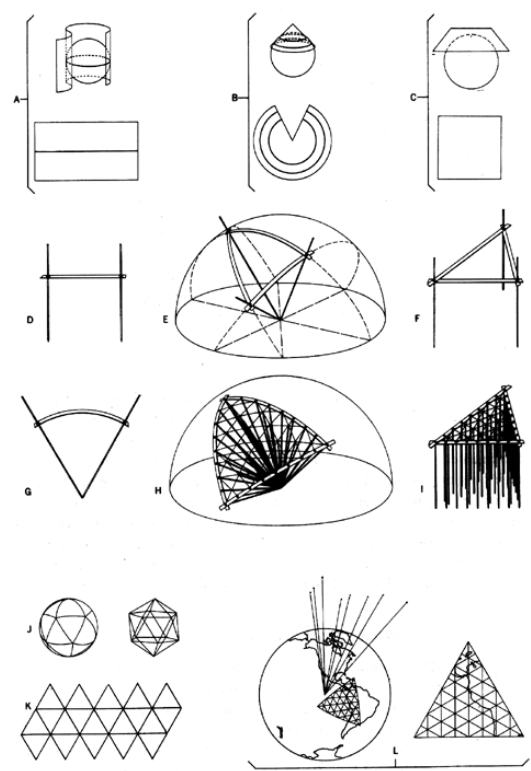

Fonte: Disponível em: http://www.rwgrayprojects.com/synergetics/s11/figs/f0102.html. Acesso em: 5 fev. 2019.

0 primeiro projeto de Fuller utilizando um domo geodésico foi concebido para a Ford Motor Company, em 1953. No entanto, um dos projetos mais famosos é o domo de Montreal, a Biosfera, feito para a Exposição Internacional de 1967 (Figura 2). Esse pavilhão americano trata-se de um domo de $76 \mathrm{~m}$ de diâmetro e $61 \mathrm{~m}$ de altura máxima. "O domo é formado por uma capa externa de triângulos, a geodésica propriamente dita, e uma camada de hexágonos que suportam cúpulas acrílicas e absorvem os esforços não contidos numa superfície" (LOTUFO; LOPES, 1981, [p. 3]). Esse projeto serviu de paradigma para que outras pessoas influenciadas por Fuller pudessem explorar esse sistema estrutural aplicado em Engenharia, Arquitetura e Design.

Figura 2: Richard Buckminster Fuller e a Biosfera.

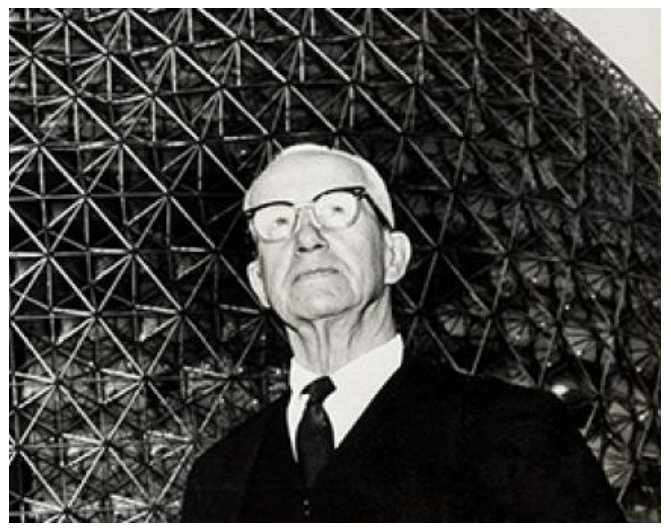

Fonte: Disponível em:

https://www.bfi.org/sites/default/files/styles/header_banner/public/images/Bucky-WorldsFair620_0.jpg?itok=mWqnCSpH. Acesso em: 5 fev. 2019. 
Outro exemplo mundialmente emblemático é a esfera geodésica chamada de Spaceship Earth, que é um símbolo do Experimental Prototype Community Of Tomorrow (EPCOT), o segundo dos quatro parques temáticos construídos no Walt Disney World, na Flórida (Figura 3).

Figura 3: Geodésica do EPCOT.

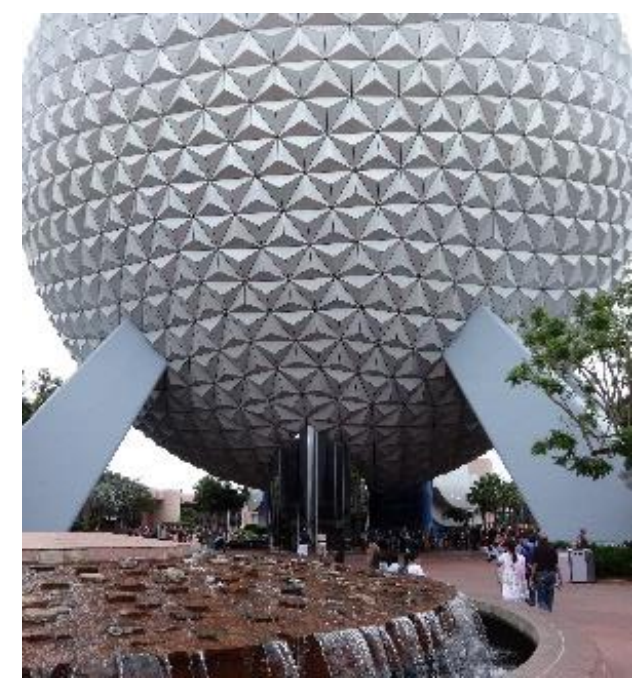

Fonte: Autor (2013).

Já no terceiro milênio, tem-se o Eden Project (Projeto Éden), de 2001, de autoria do arquiteto inglês Nicholas Grimshaw, erguida na Cornualha, Inglaterra (Figura 4), o qual tem sido mencionado como "uma interpretação moderna e bem-sucedida do conceito de domo geodésico de Buckminster Fuller" (WALSH, 2018, tradução nossa).

Figura 4: Éden Project.
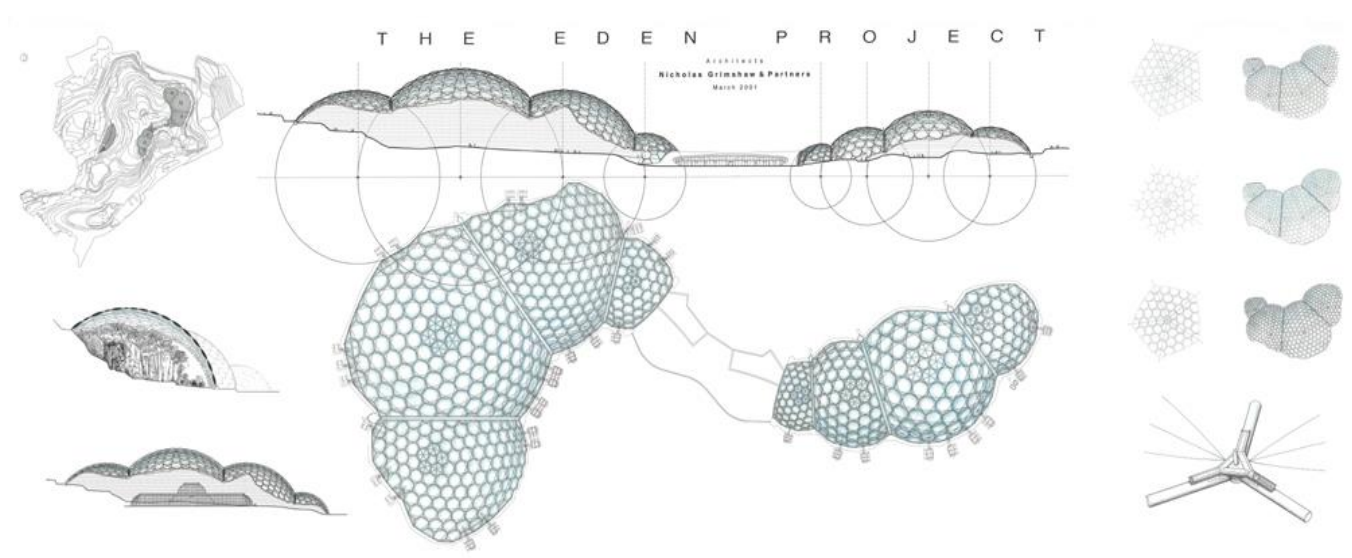

Fonte: Disponível em: https://grimshaw.global/assets/uploads/EDEN_biome_poster_2001.jpg. Acesso em: 5 fev. 2019.

No cenário brasileiro, também se encontram alguns projetos desenvolvidos tendo as geodésicas como forma. Por exemplo, no Instituto Inhotim, há algumas obras/galerias que se valem da estrutura de domos geodésicos, dentre as quais pode-se destacar a obra "De lama lâmina", de Matthew Barney, e "By means of a sudden intuitive realization" ("Por meio de uma realização intuitiva repentina"), de Olafur Eliasson. 
Figura 5: As obras “De lama lâmina” (à esquerda) e "By means of a sudden intuitive realization” (à direita), no Instiuto Inhotim.
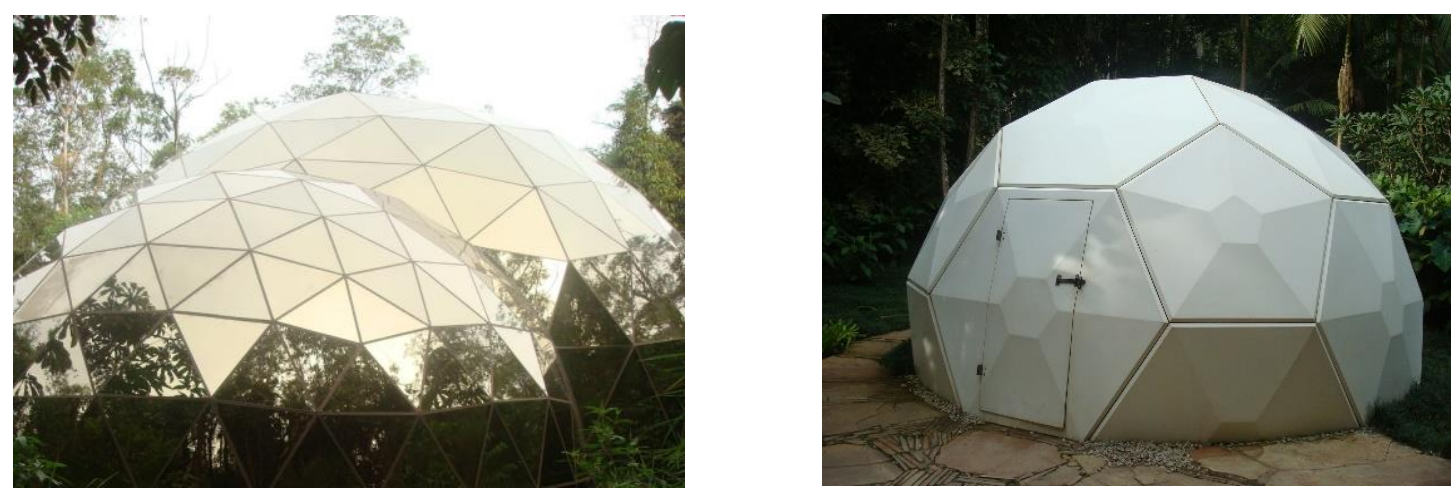

Fonte: Autor (2012).

Ainda no Brasil, no âmbito das pesquisas, o Laboratório de Investigação em Livre Desenho (LILD), vinculado à Pontifícia Universidade Católica do Rio de Janeiro (PUC-Rio), há mais de 20 anos, realiza diversos estudos inspirados pelos ensinamentos de Fuller, sobretudo com a utilização do bambu (SILVA; FARBIARZ, p. 2016).

\section{CONSTRUINDO GEODÉSICAS: DA REPRESENTAÇÃO À CONSTRUÇÃO EM ESCALA} NATURAL

Ao se buscar por casos de estudo das geodésicas no campo da Arquitetura e Urbanismo, algumas experiências pedagógicas são encontradas, visando aos diferentes objetivos. Por exemplo, parte dos trabalhos levantados dizem respeito à sustentabilidade, ao uso de materiais leves, naturais, ecológicos e/ou recicláveis, tais como papelão e bambu.

Neste artigo, são apresentadas algumas experiências desenvolvidas na Faculdade de Arquitetura e Urbanismo da Universidade Federal de Juiz de Fora (FAU/UFJF), mais especificamente no âmbito da disciplina Estudo da Forma para Arquitetura e Urbanismo, que se trata de uma disciplina obrigatória, de caráter teórico/prático, oferecida para alunos de primeiro período, ministrada no Laboratório de Modelos e Maquetes. Destacase que essa disciplina, desde a sua criação, em 2012, vem sendo recorrentemente oferecida pelos professores Frederico Braida e Juliane Figueiredo Fonseca, vinculados ao Laboratório de Estudos das Linguagens e Expressões na Arquitetura, Urbanismo e Design (LEAUD), além de contar com a colaboração de outros professores.

O estudo das geodésicas tem por objetivo principal integrar os conteúdos de sistemas estruturais, representação gráfica e projeto arquitetônico, além de história e teoria, de tal forma que os alunos passam perceber a indissociabilidade entre os diferentes saberes e as variadas disciplinas. Assim, o que se busca aqui é apresentar cinco diferentes, porém inter-relacionadas, abordagens práticas para o estudo das geodésicas, que vão desde a produção de um modelo em escala reduzida até a construção em escala natural.

\subsection{Construção de repertórios}


Ainda que já tenham visto alguma geodésica, geralmente, os alunos iniciantes nos cursos de Arquitetura e Urbanismo não possuem um repertório amplo sobre esse tipo de estrutura. Portanto, fazem-se necessárias algumas explanações sobre o tema, sobretudo integrando-se diferentes pontos de vista e os diversos campos do conhecimento humano que contribuem para o estudo das geodésicas, dentre os quais devem ser destacados: Matemática [Geometria (Representação Gráfica)], História (e Teoria), Engenharia (e Tecnologia) e Arquitetura e Urbanismo.

A partir de uma aula expositiva, fundamentada na revisão de literatura, amplamente ilustrada, os alunos são convidados a realizarem, como atividade extraclasse, buscas por novos exemplos de aplicações da geodésica em contextos arquitetônicos. Deve-se destacar que são muitas as imagens disponíveis na Internet. Com uma simples busca no "Google imagens" pelas palavras "geodésica", "domo geodésico" ou "geodesic", os alunos são capazes de encontrar inúmeros exemplos. 0 mesmo vale para buscas realizadas no "Pinterest" (Figura 6).

Figura 6: Resultado da busca pelas palavras “domo geodésico" no “Pinterest”, em 4 maio 2020.

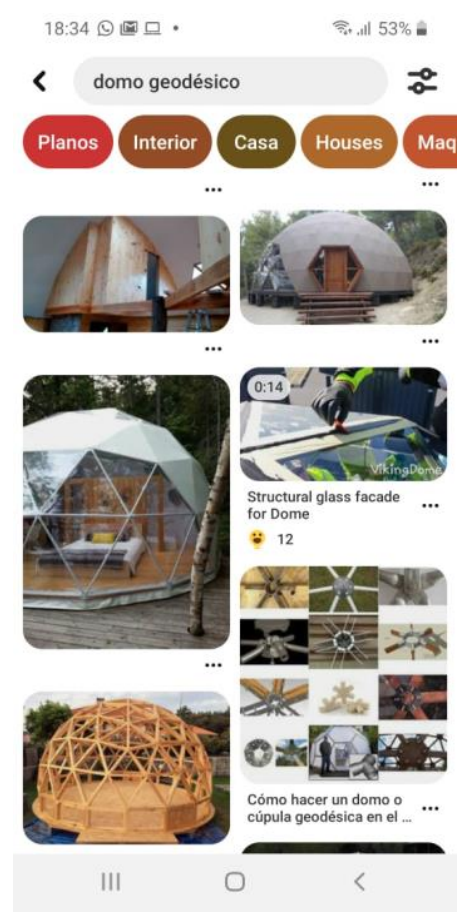

Fonte: Autor (2020).

Em uma aula seguinte, os alunos devem levar as imagens encontradas para socializarem com os demais da turma, buscando-se apresentar: (a) as soluções construtivas adotadas, (b) os materiais empregados, (c) a biografia dos autores dos projetos, (d) o local e data de construção, (e) as imagens do projeto, entre outras. Assim, os alunos tornam-se mais despertos para o tema da geodésica como objeto arquitetônico.

\subsection{Fabricação de modelos em escalas reduzidas}


Também, após a aula expositiva, os alunos formam duplas para realizarem a construção de uma geodésica de $20 \mathrm{~cm}$ de diâmetro de base, preferencialmente de frequência igual a $2 \mathrm{~V}$, de tal forma que não seja um exercício demasiadamente complicado. Para tanto, cada dupla é estimulada a buscar diferentes programas (ou sites) existentes para a realização dos cálculos.

São vários os sites e programas que se propõem a ajudar no cálculo dos domos geodésicos. A título de ilustração, pode ser citado o site "Acidome" (http://acidome.ru), no qual podem ser alterados vários parâmetros. Um diferencial desse site é que é gerado um modelo tridimensional, o qual pode ser manipulado, bem como escolhidos diferentes acabamentos. Esse site, que é bastante completo, apresenta, ainda, o desenho planificado das faces e a angulação entre elas para a montagem.

Também o site "Desert Domes" (http://www.desertdomes.com) se propõe a calcular as geodésicas a partir da inserção de diversos parâmetros. Mais um exemplo é o programa CADRE Geo 7 (https://www.cadreanalytic.com/cadregeo.htm).

De acordo com os cálculos do site Desert Domes, para uma geodésica de $10 \mathrm{~cm}$ de raio de base, de frequência $=2 \mathrm{~V}$, são necessárias 35 barras de aproximadamente $6,2 \mathrm{~cm}$ de comprimento e 30 barras de 5,5cm de comprimento, bem como 10 nós para 4 conexões, 6 nós para 5 conexões e 10 nós para 6 conexões (Figura 7).

Figura 7: Janela do site Desert Domes.

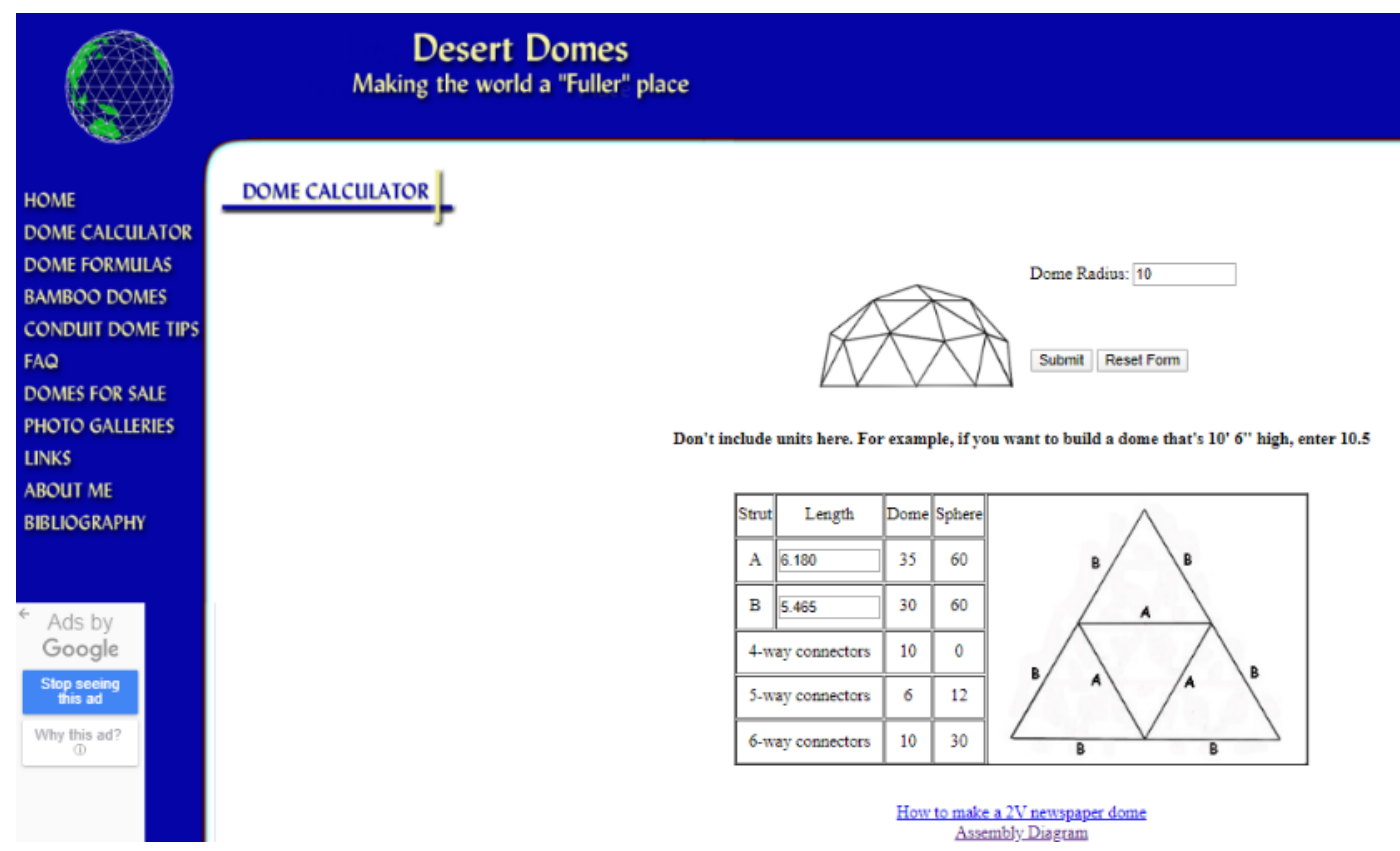

Fonte: Disponível em: http://www.desertdomes.com/dome2calc.html. Acesso em: 3 maio 2020.

Sugere-se que os alunos adotem cores diferentes para as barras, de forma a facilitar a montagem da geodésica, evitando a confusão entre as barras que, embora tenham medidas diferenciadas, são aproximadas.

Ao longo dos semestres, desde que esse exercício começou a ser realizado, os materiais foram sendo alternados (Figura 8). Recorrentemente são utilizados canudos plásticos (preferencialmente higienizados e reutilizados) conectados com linha ou barbante. Nesse caso, não são necessários os nós, pois as junções das extremidades dos 
canudos por meio de linha ou barbante já são suficientes. Outra possibilidade é a utilização de palitos de churrascos conectados com nós fabricados com garrotes de borracha. Assim, tem-se nós flexíveis o suficiente para armar a geodésica, sendo capazes de conectar as barras.

Figura 8: Modelos de geodésicas e estruturas treliçadas produzidas com diferentes materiais.
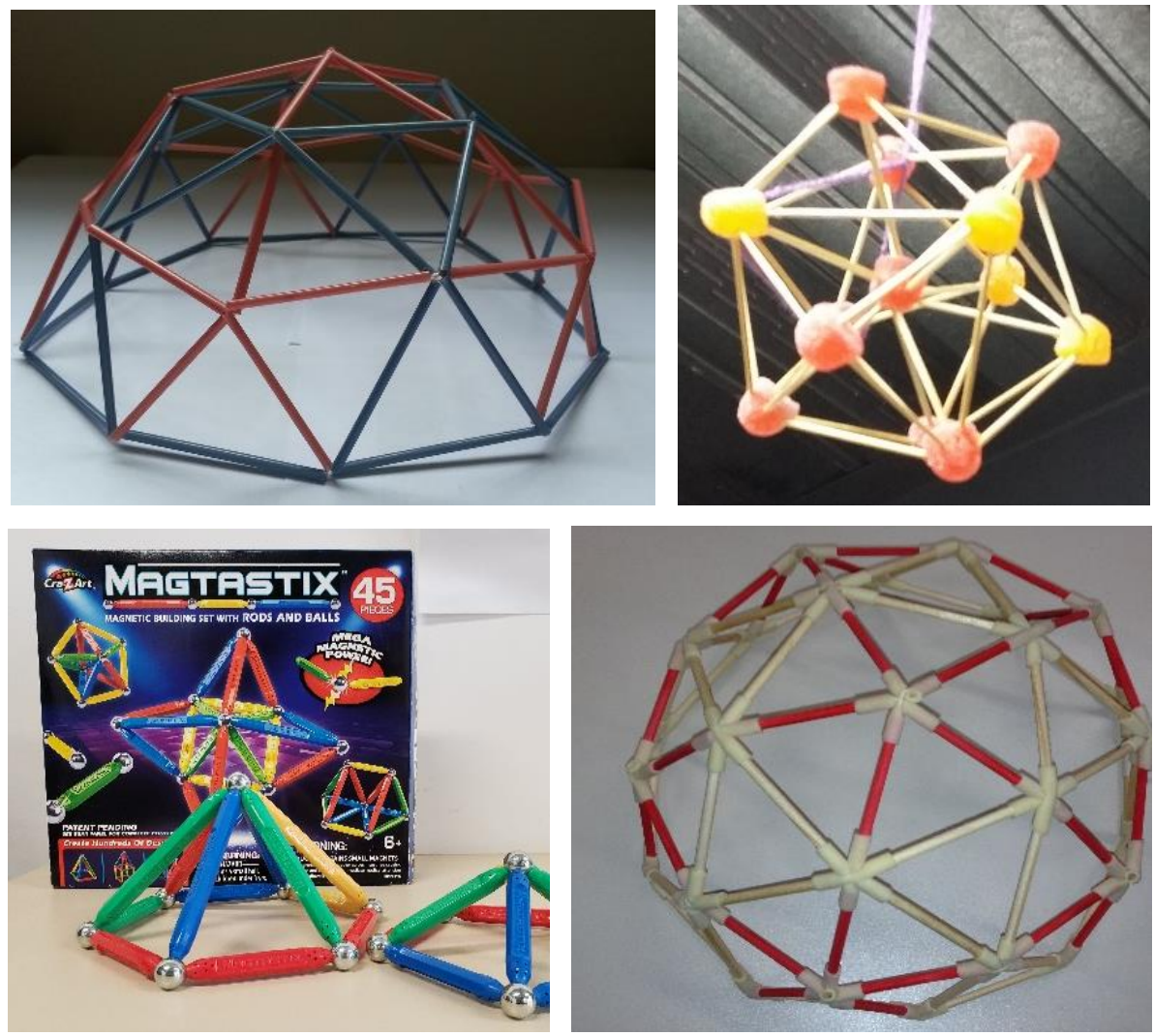

Fonte: Autor (2018).

Também, na disciplina, já foram realizados exercícios em que estruturas treliçadas foram construídas com palitos de dente (para as barras) e balas de goma (para os nós). E, além desses, outros materiais podem ser utilizados na construção de maquetes econômicas, tais como canudos de papel (fabricados pelos próprios alunos com jornal ou papel pardo) para a barras e massa de modelar infantil, massa de biscuit ou massa epóxi para os nós. Maquetes um pouco mais custosas podem ser construídas utilizando-se barras de Madeira Balsa ou com conjuntos de peças modeladas digitalmente e fabricadas com impressora 3D.

Mais recentemente, com o desenvolvimento de uma pesquisa financiada pela Fundação de Amparo à Pesquisa do Estado de Minas Gerais (FAPEMIG), desenvolvida no LEAUD/UFJF, foram adquiridos alguns jogos de montar os quais também podem ser utilizados para a construção de geodésicas. Para esse fim, destacam-se os seguintes jogos: Magtastix, cujas conexões se realização a partir de uniões magnéticas, e o Construction Fort. 


\subsection{Planificação de domos geodésicos}

Dentre os diversos conteúdos matemáticos (geométricos), também relacionados ao desenho técnico e projetivo, as geodésicas suscitam a temática da planificação. Levando-se esse escopo em consideração, os alunos podem ser chamados a planificar a geodésica, utilizando um papel cartão (um papel mais rígido, de gramatura mais elevada), de tal forma que, ao final, possa ser recortada e montada.

É interessante observar, que, quando a planificação é realizada após a montagem da primeira maquete, os alunos conseguem uma melhor compreensão, pois a abstração no plano (desenho no papel) acontece mediante um modelo físico, um material concreto já fabricado pelos alunos. Inclusive, as medidas para a realização do desenho podem ser tomadas diretamente da geodésica construída.

Para a planificação, sugere-se a adoção da escala 1:2 em relação ao modelo construído previamente. 0 desenho pode ser realizado tanto artesanalmente, com instrumentos de precisão, tais como lápis, régua e compasso, quanto com recursos de CAD (Computer Aided Design), valendo-se de programas como AutoCAD (Figura 9), CorelDRAW e PhotoShop, ou, ainda, de programas mais complexos como Rhinoceros acompanhado pelo plug-in Grasshopper. Com a inserção dos equipamentos de prototipagem rápida e de fabricação digital nas escolas de Arquitetura e Urbanismo, é possível passar diretamente do desenho computadorizado para o corte em uma máquina a laser (laser cut) ou um plotter de recorte.

Figura 9: Uma das possibilidades de planificação do domo geodésico da Figura 7, com a utilização do AutoCAD.

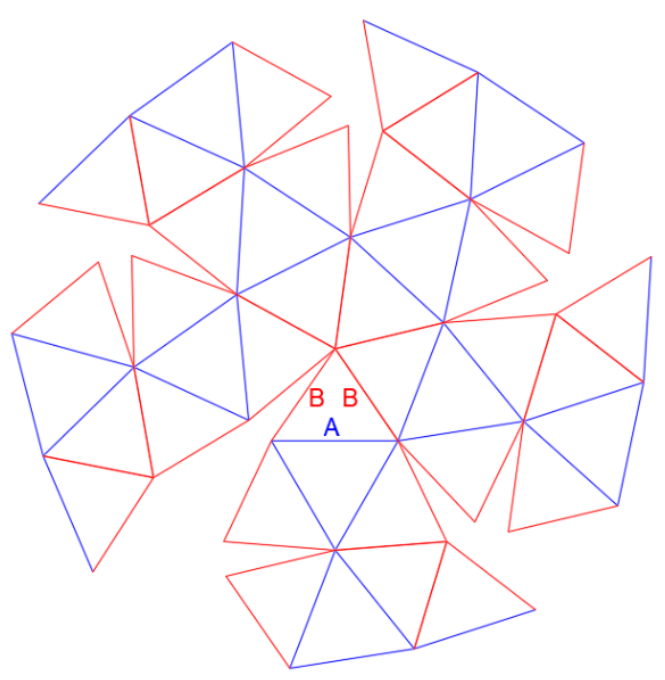

Fonte: Autor (2018).

Vele destacar que as geodésicas, para além das planificações, suscitam a abordagem de diferentes conteúdos geométricos, tais como os sólidos clássicos - os sólidos platônicos ou figuras cósmicas e os sólidos arquimedianos. Todos esses conteúdos podem ser explorados paralelamente nos exercícios de construção dos domos geodésicos.

\subsection{Simulações e projeções: as formas geodésicas como mote de projeto}


A partir da ampliação do repertório dos alunos em relação às geodésicas e da construção dos modelos, paralelamente aos processos de planificação, podem ser exploradas atividades criativas e de projeto. Na disciplina Estudo da Forma, os alunos têm sido instigados a pensar como os arquitetos podem se apropriar das geodésicas em seus projetos. Assim, concordamos com Montenegro (1991, p. 78), ao afirmar que

\begin{abstract}
a montagem de geodésicas e de poliedros (especialmente depois de terem sido estudados dois problemas fundamentais da GD - a verdadeira grandeza e a planificação) dá margem a um grande número de alternativas de construção. A montagem de maquetes deve ser associada ao desenho, a fim de desenvolver a capacidade criativa (criar coisas novas ou dar novos usos a coisas velhas, saindo da rotina) em paralelo com a destreza manual e o domínio da teoria da representação gráfica.
\end{abstract}

Ao propormos a utilização de geodésicas como ponto de partida para o projeto, estamos nos valendo de um método normativo de criação de formas arquitetônicas, detalhadamente exposto por Mahfuz (1995, p. 89 e 90). Segundo o autor, as cúpulas geodésicas são concebidas a partir de um tipo de norma representada pelos sistemas geométricos tridimensionais (MAHFUZ, 1995, p. 90).

Nesse momento, é interessante retomar as propriedades arquitetônicas e construtivas das geodésicas. De acordo com Lotufo e Lopes (1981, p. 43), são características dos domos (geodésicos): (a) proporcionam grandes volumes de espaço claro e desobstruído; (b) sua produção industrial é viável, pois é constituído de várias partes idênticas e formatos semelhantes; (c) são estruturas levíssimas; (d) são construções [relativamente] simples e não demandam mão de obra especializada.

Assim, levando-se em conta essas características, os exercícios projetuais podem ser de naturezas e graus de sofisticação diferentes. Alguns exercícios podem demandar pouco tempo, quando desenvolvidos na própria sala de aula, empregando-se o desenho de croquis, a partir da técnica de brainstorming (ou, mais especificamente, braindrawing); outros podem demandar mais tempo, sendo indicados como atividade extraclasse, com a qual se propõe a utilização de montagens (computadorizadas ou não), fotoinserções etc., ou de desenhos em perspectiva mais elaborados, criados com técnicas variadas (pintura, lápis de cor, caneta hidrocor etc.).

\title{
4.5. Construção de geodésicas em escala natural
}

Conforme ressaltam Laverde e Salado (2012), nas escolas de arquitetura ainda há um grande distanciamento entre o projeto e a prática construtiva. Embora tenhamos assistido, com a inserção das tecnologias de prototipagem rápida e de fabricação digital nos espaços de ensino, o prenúncio de uma trajetória de reversão desse quadro, o amplo desenvolvimento de atividades práticas, que levem os alunos a lidarem com problemas de natureza construtiva mais concretas, ainda se faz necessário. É nesse sentido que a construção de um domo geodésico em escala natural pode contribuir.

Na disciplina de Estudo da Forma, o exercício de construção da geodésica tem sido realizado, geralmente, no meio do semestre letivo, após as atividades anteriormente mencionadas, como uma instalação montada em algum lugar público. A geodésica tem sido montada no saguão da faculdade ou no pátio, entre o edifício principal da Faculdade 
de Arquitetura e Urbanismo e os edifícios da Faculdade de Engenharia, próximo à cantina (Figura 10).

Figura 10: Construção e instalação de geodésicas em escala natural.
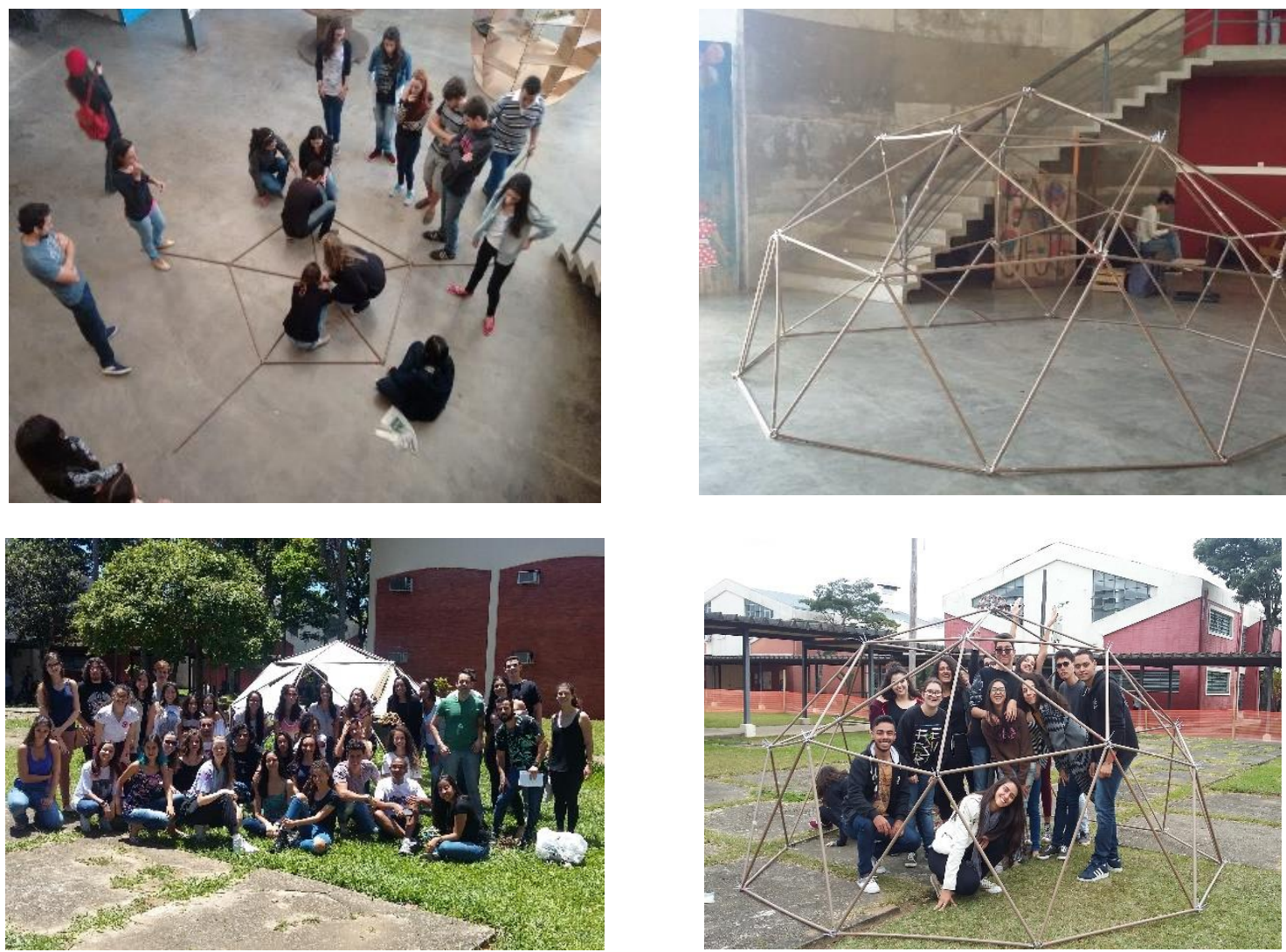

Fonte: Autor (2018).

Embora possam ser utilizados materiais diversos (variando desde tubos [tubetes ou canudos] de papelão de bobinas de papéis ou de tecidos reaproveitados até barras metálicas), a geodésica desse exercício tem sido construída com tubos (canos) de policloreto de vinila (PVC) conectados com nós também cortados em PVC e unidos com abraçadeiras plásticas (de Nylon). Com esses materiais, consegue-se uma estrutura leve, resistente o suficiente para suportar o peso próprio, podendo ficar exposto às intempéries e de baixo custo. Quando desmontada, as peças são guardadas para ser reutilizadas em instalações futuras.

\section{CONSIDERAÇÕES FINAIS}

Conforme evidenciado neste artigo, a temática da geodésica se mostra bastante pertinente para uma abordagem interdisciplinar entre Geometria, Arquitetura e Engenharia, perpassando diferentes dimensões do projeto, da história e da teoria, da representação gráfica e da tecnologia construtiva.

O que se buscou apresentar foi um encadeamento de atividades tendo como tema gerador as geodésicas. Portanto, para além de um enfoque na temática específica, do ponto de vista metodológico, este artigo expõe alguns exercícios de uma sequência 
didática pautada por experiências dialógicas (e não paradoxais) entre a teoria e a prática, entre a abstração e a materialização, entre a representação gráfica bidimensional e a tridimensional, que vão desde a produção de protótipos até a construção em escala natural.

Cumpre, à guisa de conclusão, a partir das experiências trazidas à baila, mencionar que a produção de geodésicas, seja durante a realização de maquetes ou na montagem em tamanho natural, até mesmo em função do aspecto lúdico envolvido na execução das tarefas propostas, tem envolvido os alunos, os quais têm se mostrado muito empenhados na busca por novos conhecimentos e motivados a compreender as relações geométricas, técnicas e estéticas subjacentes ao projeto arquitetônico e à construção civil.

\section{REFERÊNCIAS}

AMORIM, Anália M. M. C. Diálogos entre forma arquitetônica e sua concepção estrutural. In: PERRONE, Rafael Antonio Cunha; VARGAS, Heliana Comin (Orgs.). Fundamentos de projeto: arquitetura e urbanismo. São paulo: EDUSP, 2014. p.138-145.

CHING, Francis D. K. Dicionário visual de arquitetura. São Paulo: Martins Fontes, 2000.

DINIZ, João Antônio Valle. Estruturas geodésicas: estudos retrospectivos e proposta para um espaço de educação ambiental. Dissertação (Programa de Pós-Graduação em Engenharia Civil). Universidade Federal de Ouro preto. 2006.

ENGEL, Heino. Sistemas estruturais. Barcelona: Gustavo Gili, 2001.

FULLER, Richard Buckminster. Synergetics: explorations on the geometry of thinking. New York: [s.n.], 2002. Disponível em:

http://www.rwgrayprojects.com/synergetics/synergetics.html. Acesso em: 2 jul. 2018.

LAVERDE, Albenise; SALADO, Gerusa de Cássia. Construção de uma cúpula geodésica com tubos de papelão: uma experiência na Universidade Federal De Uberlândia UFU/MG. In: CONGRESSO BRASILEIRO DE EDUCAÇÃO EM ENGENHARIA, 40. Anais [...] Belém/PA: ABENGE, 2012. Disponível em:

http://www.abenge.org.br/cobenge/arquivos/7/artigos/103924.pdf. Acesso em: 2 jul. 2018.

LOPES, João Marcos; BOGÉA, Marta; RABELLO, Yopanan. Arquiteturas da engenharia, ou, engenharias da arquitetura. São Paulo: Mandarim, 2006. p.9 e 10.

LOTUFO, Vitor Amaral; LOPES, João Marcos A. Geodésicas e cia. São Paulo: Projeto, 1981.

MAHFUZ, Edson da Cunha. Ensaio sobre a razão compositiva: uma investigação sobre a natureza das relações entre as partes e o todo na composição arquitetônica. Viçosa: UFV; Belo Horizonte: AP Cultural, 1995. 
MARQUES, Diogo. Domos geodésicos: o que são e quais suas vantagens para a construção sustentável. SustentArqui. 2016. Disponível em:

https://sustentarqui.com.br/domos-geodesicos-vantagens/. Acesso em: 15 nov. 2018.

MONTENEGRO, Gildo A. Geometria descritiva. São Paulo: Blucher, 1991.

MONTENEGRO, Gildo A. Ventilação e cobertas: estudo teórico, histórico e descontraído. São Paulo: Blucher, 1984.

SILVA, Julia Teles da; FARBIARZ, Jackeline Lima. O pensamento de Buckminster Fuller e o LILD, PUC-RIO. In: Anais do 12 Congresso Brasileiro de Pesquisa e Desenvolvimento em Design [= Blucher Design Proceedings, v. 9, n. 2]. São Paulo: Blucher, 2016. p. 1999-2010. Disponível em: http://pdf.blucher.com.br.s3-sa-east1.amazonaws.com/designproceedings/ped2016/0170.pdf. Acesso em: 10 fev. 2018.

VANDYKE, Scott. From line to design: design graphics comunication. 2. ed. Mesa (Arizona, EUA): PDA Publischers, 1985.

VASCONCELOS, Augusto Carlos de. Prefácio: a poética da estrutura na beleza da obra. In: LOPES, João Marcos; BOGÉA, Marta; RRABELLO, Yopanan. Arquiteturas da engenharia, ou, engenharias da arquitetura. São Paulo: Mandarim, 2006. p. 9 e 10.

VERSCHLEISSER, Roberto. Aplicação de estruturas de bambu no design de objetos: como construir objetos leves, resistentes, ecológicos e de baixo custo. Tese (Programa de Pós-Graduação em Design). Pontifícia Universidade Católica do Rio de Janeiro. Rio de Janeiro, 2008. Disponível em: https://www.maxwell.vrac.puc-

rio.br/colecao.php?strSecao=resultado\&nrSeq=12258@1. Acesso em: 5 fev. 2018.

VILLASUSO, Bernardo Marcelo. El espacio arquitectónico: la estrutura portante. Buenos Aires: El Ateneo, 2009.

WALSH, Niall Patrick. Grimshaw's next Eden Project could be in the North of England. ArchDaily. 10 set. 2018. Disponível em:

https://www.archdaily.com/901136/grimshaws-next-eden-project-could-be-in-thenorth-of-england/. Acesso em: 10 abr. 2020.

\section{AGRADECIMENTOS}

Os agradecimentos são direcionados à Fundação de Amparo à Pesquisa do Estado de Minas Gerais (FAPEMIG) - Processos TEC APQ 01041/14 e TEC PPM 00766/15, a qual viabilizou financeiramente as pesquisas das quais geraram parte das reflexões apresentadas neste artigo, e à Profa. Dra. Juliane Figueiredo Fonseca, com a qual tenho compartilhado algumas reflexões e pesquisas ao longo dos últimos anos. Devo, ainda, agradecer aos monitores, mestrandos (estagiários de docência) e aos alunos da disciplina na qual foram desenvolvidos os exercícios relatados neste artigo. 